\title{
Perawatan Metode Kanguru (PMK) Mempersingkat Lama Rawat Bayi Baru Lahir
}

\author{
Yohana Yuniarti Fitri ${ }^{1}$, Bambang Suryadi ${ }^{2}$ \\ 1,2Program Studi Ilmu Keperawatan \\ Sekolah Tinggi Ilmu Kesehatan Indonesia Maju \\ Jln. Harapan nomor 50, Lenteng Agung-Jakarta Selatan 12610 \\ Telp: (021) 78894045, Email: 'yohana@ gmail.com, ${ }^{2}$ bambangsuryadi@ gmail.com
}

\begin{abstract}
Abstrak
Kematian bayi merupakan bagian dari salah satu masalah bagi kesehatan, salah satu faktor yang menyebabkan hal tersebut yaitu Bayi Berat Lahir Rendah (BBLR) yang mengakibatkan lama rawat, hal yang dapat dilakukan untuk mengatasi tindakan yang dilakukan yaitu dengan melakukan Perawatan Metode Kangguru (PMK). Tujuan dari penelitian ini untuk mengetahui Hubungan PMK dengan lama rawat pada BBLR. Penelitian ini menggunakan analitik deskriptif dengan pendekatan retrospektif pada 99 responden. Uji statistic dalam penelitian ini menggunakan chi square dengan teknik pengambilan sampel yang digunakan peneliti adalah total sampling. Hasil penelitian didapatkan bahwa mayoritas responden melakukan PMK rutin sebanyak $83,8 \%$ dan lama rawat singkat sebanyak $65,7 \%$ terdapat hubungan yang signifikan antara PMK dengan lama rawat pada BBLR $(\mathrm{P}=0,001)$. Hal tersebut dapat dijadikan rekomendasi pemberian edukasi bahwa PMK rutin dilakukan untuk mempersingkat lama rawat.
\end{abstract}

Kata Kunci : : BBLR, Lama rawat, Perawatan metode kangguru.

\begin{abstract}
Infant mortality is part of one of the problems for health, one of the factors that causes it is the Low Birth Weight $(L B W)$ which results in long care, HAL that can be done to overcome the actions taken, namely by doing the Care of the Kangaroo Method (PMK). The purpose of this study was to determine the relationship of FMD with length of stay in LBW. This study uses descriptive analytics with a retrospective approach on 99 respondents. The statistical test in this study using chisquaer with the sampling technique used by researchers was total sampling. The results showed that the majority of respondents did routine PMK as much as $83.8 \%$ and short length of stay of $65.7 \%$ there was a significant relationship between $P M K$ and length of stay in $L B W(P=$ 0.001). This can be used as a recommendation for education that routine PMK is done to shorten the length of stay.
\end{abstract}

Keywords $\quad$ : Length of stay, LBW, Kangaroo method treatment. 


\section{Pendahuluan}

Angka kematian bayi (AKB) merupakan salah satu indikator kualitas kesehatan masyarakat di suatu negara. WHO mengatakan bahwa setiap tahun di dunia terdapat 4 juta bayi yang meninggal dalam periode neonatal. Menurut perkiraan WHO pada tahun 2013 masih banyak terjadi AKB di Negara berkembang hampir semua (98\%) dari 5 juta kematian neonatal. Penyebab utama dari kematian bayi adalah prematur dan bayi berat lahir rendah (BBLR), infeksi, asfiksia (kekurangan oksigen saat lahir) serta trauma lahir. Hal ini menyebabkan hampir $80 \%$ kematian terjadi pada usia ini. ${ }^{1}$

Prevalensi bayi dengan BBLR diprediksi $15 \%$ dari semua kelahiran yang ada di dunia dengan batasannya 3,3\% - 38\% serta terjadi lebih sering pada beberpa negara berkembang dengan sosial dan ekonomi rendah. Berdasarkan data statisik ditunjukan bahwa 90\% kejadian BBLR ditemui di negara berkembang serta angka kematian 35 kali lebih dari 2500 gram. ${ }^{2}$

Berdasarkan data SDKI bahwa kejadian AKB di Indonesia ialah 35 bayi per 1000 kelahiran. kematian bayi sebagian besar disebabkan masalah yang terjadi pada bayi baru lahir atau neonatal diantara umur 0 hinga 28 hari, kejadian BBLR ialah salah satu faktor yang memiliki kontribusi tpada kematian bayi pada masa neonatal khususnya. ${ }^{3}$

BBLR merupakan kondisi bayi yang dilahirkan dengan berat kurang dari 2500 gram tanpa memandang usia gestasi. BBLR dapat disebabkan oleh bayi lahir kurang bulan (usia kehamilan kurang dari 37 minggu), pertumbuhan janin yang terhambat (PJT) atau kombinasi dari keduanya (Dwienda, 2014).Masalah pada bayi BBLR terutama terjadi karena ketidakmatangan sistem organ pada bayi tersebut. Masalah pada bayi BBLR yang sering terjadi adalah gangguan termoregulasi, gangguan pada sistem pernafasan, kardiovaskular, hematologi, gastrointestinal, susunan saraf pusat dan ginjal. $^{4}$

Hasil penelitian yang dilakukan pada tahun 2014 di Ruang Perinatologi RSUD Arifin Achmad Pekanbarumenjelaskan bahwa rata-rata lama hari rawat pada responden yang mengalami morbiditas kompleks yaitu 15.81 hari rawat, sedangkan minimum hari rawat adalah 2 hari dan maksimum 75 hari. Rata-rata lama hari rawat untuk responden dengan morbiditas non-kompleks yaitu 7.08 hari rawat dengan minimum hari rawat adalah 1 hari dan maksimum 26 hari. $^{5}$

Bayi dengan BBLR membutuhkan peralatan khusus seperti incubator untuk membantu bayi menjaga kehangatan tubuh dan menciptakan lingkungan seperti lingkungan di intrauterine. Metode alternatif biasa digunakan dapat mengatasi permasalahan termoregulasi pada bayi BBLR ialah Perawatan Metode Kanguru (PMK). Perawatan metode tersebut dapat dikatakan lebih ekonomis dikarenakan hanya membutuhkan kulit ibu untuk media penghantar panas. Selain itu dapat menjaga kestabilan suhu tubuh serta PMK juga bisa memberikan bounding antara ibu serta bayi, melatih ibu pada pemberian ASI (breastfeeding) serta melatih ibu agar memberikan kehangatan tubuhnya secara alami kepada bayi, sehingga bayi tidak perlu terus menerus menggunakan incubator untuk menjaga kehangatan tubuhnya. Selain karena keterbatasan fasilitas, biasanya bayi BBLR membutuhkan waktu perawatan yang cukup lama di rumah sakit sampai kondisi bayi stabil. $^{6}$

Studi pendahuluan didapatkan bahwa di RSUD Cengkareng pada 2017 terdapat 34 kasus BBLR dari 135 kelahiran total. Rumah sakit ini biasanya dijadikan sebagai rumah sakit rujukan untuk kasus bayi dengan BBLR biasanya dilakukan perawatan di ruang perinatologi. Namun, fenomena di lapangan yang terjadi adalah tidak semua bayi dengan BBLR dapat ditempatkan di incubator karena keterbatasan biaya atau peralatan yang tersedia di rumah sakit. Sering kali jumlah bayi yang membutuhkan incubator lebih banyak daripada peralatan yang dimiliki oleh rumah sakit. Oleh karena itu, diperlukan suatu metode alternatif yang ekonomis danefisien sebagai pengganti incubator.

Dari jumlah sampel 10 yang diamati,3 bayi yang dilakukan PMK dengan berat badan $\leq 1500$ gram rata-rata lama perawatan untuk bayi BBLR adalah 6 - 15 hari, sedangkan 7 bayi yang tidak dilakukan $P M K \geq 16-30$ hari ,tetapi biasanya tergantung dengan berat badan lahirbayi. Berdasarkan fenomena di atas maka Peneliti tertarik untuk melakukan penelitian tentang Hubungan Perawatan Metode Kanguru (PMK) Terhadap Lamanya Hospitalisasi Bayi 
BBLR diruang Perinatologi RSUD Cengkareng Tahun 2018.

Tujuan penelitian ini adalah untuk Mengetahui Hubungan Perawatan Metode Kanguru (PMK) Dengan Lama Rawat Pada Bayi Berat Lahir Rendah (BBLR) Diruang Perinatologi RSUD CengkarengTahun 2018.

\section{Metode}

Desain penelitian adalah Rancangan penelitian yang digunakan adalah rancangan penelitian korelasidengan pendekatan retrospektif. Penelitian korelasi ini bertujuan untuk mengetahui hubungan dan tingkat hubungan antara dua variabel atau lebih tanpa ada upaya untuk mempengaruhi variabel tersebut sehingga tidak terdapat manipulasi variabel. Studi kasus-kontrol sering disebut studi retrospektif karena faktor risiko diukur dengan melihat kejadian masa lampau untuk mengetahui ada tidaknya faktor risiko yang dialami. $^{7}$

Populasi adalah wilayah generalisasi yang terdiri atas obyek / subyek yang mempunyai kualitas dan karateristik tertentu yang ditetapkan oleh peneliti untuk dipelajari dan kemudian ditarik kesimpulan. ${ }^{8}$ Populasi adalah setiap objek yang memenuhi kriteria yang telah ditetapkan. ${ }^{9}$ Dalam penelitian ini populasinya adalah semua bayi berat lahir rendah yang sedang menjalani perawatan diruang Perinatologi RSUD Cengkareng. Jumlah keseluruhan populasi bayi dalam Bulan Januari - Desember 2018 yang peneliti ambil dari data rekam medis bayi berat lahir rendah adalah 99 bayi yang dilakukan PMK.

Sampel menggunakan formula sederhana untuk populasi dibawah 10.000 dengan tingkat kepercayaan $90 \%$ dan tingkat penyimpangan $10 \%$, maka didapat besar sampel. Teknik pengambilan sampel mengunakan total sampling yaitu memilih sampel sesuai dengan jumlah populasi dimana data diambil pada bayi BBLR yang dirawat mulai bulan Januari sampai dengan Desember 2018. Sampel penelitian ini yaitu 99 responden.

Penelitian ini dilakukan di ruang perinatologi RSUD Cengkareng. Selain itu RSUD Cengkareng merupakan Rumah Sakit Tipe B yang menjadi salah satu Rumah Sakit rujukan pemerintah Provinsi DKI Jakarta dan sekitarnya. Penelitian dan pengambilan data dilakukan peneliti antara periode bulan Januari - Desember 2018 di RSUD Cengkareng.

Analisa univariat dipergunakan untuk mendapatkan gambaran distribusi frekuensi dari variabel independen maupun variabel dependen. Data pada analisa univariat ini dijadikan dalam bentuk data kategorik dengan peringkasan data menggunakan distribusi frekuensi dengan ukuran persentase (\%) atau proporsi. Untuk mengetahui distribusi frekuensi bayi BBLR dari variabel independen yang akan dianalisis dengan analisis univariat.

Analisis data kategorik menggunakan jumlah dan proporsi, sedangkan data numerik dianalisis dengan menggunakan mean, median, Standard Deviasi (SD) dan minimummaksimum pada $95 \%$ Confidence Interval $(C I)$. Analisa bivariat ini dilakukan untuk mengetahui ada atau tidaknya hubungan PMK dengan lama rawat dengan variabel dependen. Analisis ini menggunakan uji statistik yaitu uji Chi-square $\left(\mathrm{X}^{2}\right)$ dengan nilai a $=0,05$. Ada hubungan bermakna apabila $\mathrm{p}<0,05$ sebaliknya jika $p>0,05$ maka hasil penelitian tidak bermakna.

\section{Hasil}

Tabel 1. Distribusi frekuensi Usia Gestasi, Berat Badan, perawatan metode kanguru, Lama Hari Rawat di ruang perinatologi RSUD Cengkareng Jakarta Januari - Desember 2018

\begin{tabular}{ccc}
\hline Variabel & $\begin{array}{c}\text { Frekuensi } \\
(\mathbf{n})\end{array}$ & $\begin{array}{c}\text { Presentase } \\
(\boldsymbol{\%})\end{array}$ \\
\hline Usia Gestasi & 16 & 16.2 \\
30 minggu & 10 & 10.1 \\
31 minggu & 11 & 11.1 \\
32 minggu & 20 & 20.2 \\
33 minggu & 42 & 42.4 \\
34 minggu & & \\
Berat Badan & 21 & 21.2 \\
$1300-1399$ & 12 & 12.1 \\
$1400-1499$ & 14 & 14.1 \\
$1500-1599$ & 8 & 8.1 \\
$1600-1699$ & 6 & 6.1 \\
$1700-1799$ & 7 & 7.1 \\
1800-1899 & 8 & 8.1 \\
1900-1999 & 23 & 23.2 \\
2000-2099 & & \\
Perawatan & & \\
Metode & & \\
Kanguru & 16 & 16.2 \\
Tidak Rutin & 83 & 83.8 \\
Rutin & & \\
Lama \\
rawat
\end{tabular}




\begin{tabular}{lll}
\hline $\begin{array}{l}\text { Lama }(>15 \\
\text { hari })\end{array}$ & 34 & 34.3 \\
$\begin{array}{l}\text { Singkat }(\leq 15 \\
\text { hari) }\end{array}$ & 65 & 65.7 \\
\hline
\end{tabular}

Sumber : Data Primer 2018

Tabel 2. Hubungan Perawatan Metode Kanguru (PMK) Dengan Lama Rawat Pada Bayi Berat Lahir Rendah (Bblr) Diruang Perinatologi Rsud Cengkareng Tahun 2018

\begin{tabular}{|c|c|c|c|c|c|c|c|c|}
\hline \multirow{3}{*}{ Variabel } & \multicolumn{4}{|c|}{ Lama Hari Rawat } & \multirow{2}{*}{\multicolumn{2}{|c|}{ Total }} & \multirow{3}{*}{ P value } & \multirow{3}{*}{ OR } \\
\hline & \multicolumn{2}{|c|}{ Lama } & \multicolumn{2}{|c|}{ Singkat } & & & & \\
\hline & $\mathbf{N}$ & $\%$ & $\mathbf{N}$ & $\%$ & $\mathbf{N}$ & $\%$ & & \\
\hline \multirow{2}{*}{\multicolumn{9}{|c|}{$\begin{array}{l}\text { Perawatan Metode } \\
\text { Kanguru }\end{array}$}} \\
\hline & & & & & & & & \\
\hline Rutin & 4 & 4,0 & 61 & 93,8 & 65 & 100,0 & \multirow[t]{2}{*}{0,001} & \multirow{2}{*}{$\begin{array}{c}8,318 \\
(2,426-8,518)\end{array}$} \\
\hline Total & 16 & 16,2 & 83 & 61,6 & 99 & 100,0 & & \\
\hline
\end{tabular}

Sumber : Data Primer 2018

Berdasarkan Tabel 1 bahwa dari 99 responden yang dirawat di di ruang perinatologi sebagian besar memiliki usia gestasi 34 minggu sebanyak 42 responden $(42,4 \%)$. Bahwa dari 99 responden yang dirawat di di ruang perinatologi sebagian besar memiliki berat badan 2000-2099 gram sebanyak 23 responden. Diperoleh data bahwa dari 99 responden yang dirawat di di ruang perinatologi rutinitas melakukan PMK sebanyak 83 responden $(83,8 \%)$. Bahwa dari 99 responden yang dirawat diruang perinatologi rutinitas memiliki lama rawat singkat sebanyak 65 responden $(65,7 \%)$.

Berdasarkan tabel 2 terdapat hubungan yang signifikan antara PMK dengan lama rawat pada BBLR di RSUD Cengkareng $(\mathrm{P}=0,001)$ Dimana bayi BBLR yang dilakukan PMK maka lama rawatnya akan semakin singkat. Didapatkan nilai OR sebesar 8,318 dengan $95 \% \mathrm{CI}=2,426-28,518$ yang artinya bahwa semakin rutin dilakukan PMK maka hari rawatnya juga akan semakin singkat, dan sebaliknya semakin tidak rutin dilakukan PMK maka hari rawatnya juga semakin lama.

\section{Pembahasan}

\section{Distribusi Frekuensi Berdasarkan Usia Gestasi di ruang Perinatologi RSUD Cengkareng Jakarta Januari-Desember 2018}

Masa gestasi kurang dari 37 minggu dan berat badannya sesuai dengan berat badan untuk masa gestasi berat atau biasa disebut neonatus kurang bulan sesuai untuk masa kehamilan (NKB - SMK). Sedangkan dismaturitas merupakan bayi lahir dengan berat badan kurang dari berat badan seharusnya untuk masa gestasi itu. Berat bayi mengalami retardasi pertumbuhan intrauterine dan merupakan bayi yang kecil untuk masa kehamilannya. ${ }^{10}$

Bayi yang lahir terutama pada bayi dengan berat badan lahir rendah, berat badan bayi tersebut sesuai dengan usia gestasinya. Seperti usia gestasi yang kurang dari 37 minggu maka berat badan bayi tersebut kuang dari 2500gram sehingga disebut dengan berat badan lahir rendah. ${ }^{11}$

Dari hasil penelitian, dasar teori dan penelitian sebelumnya maka dapat diasumsikan bahwa usia gestasi memiliki pengaruh yang signifikan terhadap terjadinya bayi lahir dengan berat badan lahir rendah. Misalnya bayi yang memiliki berat badan lahir rendah biasanya usia gestasinya juga kurang bulan seperti kurang dari 37 minggu. Hal ini disebabkan karena adanya masalah yang terjadi pada ibu, bayi atau pada kehamilannya. Seperti contoh ibu hamil dengan gizi kurang, dapat menyebabkan bayi kurang asupan nutrisi sehingga saat lahir berat badannya kurang.

Distribusi Frekuensi Berdasarkan Berat Badan di ruang Perinatologi RSUD Cengkareng Jakarta Januari-Desember 2018

BBLR adalah bayi yang lahir dengan berat badan kurang atau sama dengan 2500 gram tanpa memandang masakehamilannya. Sehingga dalam penelitian ini berat badan bayi kurang dari 2500 gram. BBLR dapat dikelompokkan menjadi prematuritas murni dan dismaturitas. Prematuritas murni adalah bayi dengan masa kehamilan kurang dari 37 minggu dan berat badan sesuai dengan berat badan untuk usia kehamilan. Sedangkan dismaturitas adalah bayi dengan berat badan 
kurang dari berat badan seharusnya untuk usia kehamilan, hal ini menunjukkan bahwa bayi tersebut mengalami retardasi pertumbuhan intrauterine. ${ }^{12}$

Faktor-faktor penyebab terjadinya BBLR adalah karena dari faktor ibu, faktor janin dan faktor kehamilan kehamilan. Dimana faktor dari ibu seperti adanya gizi yang kurang, faktor dari kehamilan seperti adanya masalah dalam kehamilannya, dan faktor dari janin seperti adanya infeksi rahim, cacat bawaan. ${ }^{13}$

Menyatakan bahwa Perawatan Metode Kanguru Terhadap Perubahan Berat Badan Bayi Lahir Rendah diruanginap perinatologi RSUD dr.Achmad Mochtar Bukit tinggi tahun 2014 didapatkan hasil bahwa rata-rata berat badan bayi sebelum perawatan metode kanguru adalah 1738,60 gram, sedangkan setelah dilakukan perawatan metode kanguru berat badan bayi meningkat. Dapat disimpulkan bahwa terdapat pengaruh perawatan metode kanguru terhadap perubahan berat badan bayi BBLR di ruang inap perinatologi RSUD dr.Achmad Mochtar Bukittinggi tahun 2014. Disarankan kepada ibu-ibu untuk melakukan perawatan metode kanguru secara rutin dan pemberian ASI yang cukup terhadap bayi BBLR. ${ }^{14}$

Hasil penelitian, dasar teori dan penelitian sebelumnya dapat diasumsikan bahwa dengan adanya BBLR yang terjadi ini disebabkan karena 3 hal seperti faktor dari ibu yang mengandung, faktor dari kehamilan dan adanya faktor dari janin itu sendiri. Oleh sebab itu untuk menghindarai adanya kejadian berat badan lahir rendah bagi ibu hamil diharapkan sering kontrol ke sarana kesehatan supaya jika terjadi sesuatu dengan masalah kehamilannya baik dari segi ibu, kehamilan dan janin dapat sesegera mungkin teratasi dengan baik.

\section{Distribusi Frekuensi Berdasarkan Perawatan Metode Kanguru di ruang Perinatologi RSUD Cengkareng Jakarta Januari - Desember 2018}

Prinsip dasar dari metode kanguru ini adalah mengganti perawatan BBL dalam inkubator dengan metode kanguru. Hal ini disebabkan karena kurangnya fasilitas terutama inkubator dan tenaga kesehatan dalam perawatan bayi baru lahir, penggunaan inkubator memiliki beberapa keterbatasan antara lain, memerlukan tenaga listrik dan memudahkan infeksi nosokomial, rujukan ke rumah sakit untuk bayi BBLR sangat tinggi sebelum dilakukan metodekanguru. ${ }^{15}$

Menyatakan bahwa dengan adanya metode kanguru maka dapat mendekatkan kontak batin anak dengan ibunya, sehingga morbiditas bayi dengan berat badan lahir rendah (BBLR) di ruang perinatologi RSUD Arifin Achmad Pekanbaru, didapatkan lama hari rawat pada bayi dengan BBLR yang mengalami morbiditas kompleks yaitu 15,81 hari rawat dengan minimum hari rawat adalah 2 hari dan maksimum 75 hari. $^{5}$

Dari hasil penelitian, dasar teori dan penelitian sebelumnya maka dapat diasumsikan bahwa dengan adanya perawatan metode kanguru terbukti mempersingkat lama rawat juga dapat sebagai incubator yang alami, tidak ada resiko adanya listrik maupun infeksi nosokomial. Dengan semakin cepatnya perawatan di rumah sakit (kurang dari 15 hari) maka dapat mengurangi cost rumah sakit.

Hal ini menunjukkan bahwa sebagian besar responden bayi BBLR yang dirawat di ruang perinatologi sudah rutin dalam menerapkan perawatan metode kanguru, karena sudah menganggap perawatan pemakaian perawatan metode kanguru lebih bagus dibandingkan dengan incubator. Tetapi dalam perawatan dengan incubator juga terdapat resiko terhadap listrik, panas, dan jika tidak bersih dalam perawatan bisa beresiko nosokomial.

\section{Distribusi Frekuensi Berdasarkan Lama Hari Rawat Bayi BBLR di ruang Perinatologi RSUD Cengkareng Jakarta Januari - Desember 2018}

Hasil penelitian ini diperoleh data bahwa dari 99 responden yang dirawat di di ruang perinatologi yang memiliki lama hari rawat dalam kategori singkat sebanyak 65 responden $(65,7 \%)$ dan lama sebanyak 34 responden $(34,3 \%)$. Hal ini menunjukkan bahwa sebagian besar pasien bayi BBLR yang lama hari perawatannya dalam kategori singkat (kurang dari 15 hari) karena bayi BBLR sudah stabil untuk perawatan dirumah. Selain itu juga orang tua juga sudah siap dalam melakukan perawatan di rumah.

Bayi BBLR memiliki kondisi yang berbeda-beda, Ada yang lahir tanpa kondisi penyerta / komplikasi. Kelompok ini akan memiliki kesempatan lebih baik untuk pulang dari RS lebih awal dalam kondisi yang sehat. 
Sementara bayi yang lain mungkin memiliki kondisi penyerta prematuritas, yang ditemui sejak lahir atau terjadi setelah lahir. Kondisi penyerta ini bisa membuat bayi dirawat lebih lama, dan membutuhkan perawatan khusus setelah dibolehkan pulang dari RS. Bayi BBLR yang dirawat bisa diperbolehkan pulang jika sudah tercapai target pertumbuhannya (khususnya berat badan), kondisinya stabil, tidak memiliki masalah saat pemberian ASI, dan orang tua sudah siap merawatnya secara mandiri di rumah tanpa bantuan tenaga medis. menyatakan bahwa perawatan bayi BBLR adalah rata-rata 15 hari. ${ }^{16}$

Menyatakan bahwa dengan adanya metode kanguru maka dapat mendekatkan kontak batin anak dengan ibunya, sehingga morbiditas bayi dengan berat badan lahir rendah (BBLR) di ruang perinatologi RSUD Arifin Achmad Pekanbaru, didapatkan lama hari rawat pada bayi dengan BBLR yang mengalami morbiditas kompleks yaitu 15,81 hari rawat dengan minimum hari rawat adalah 2 hari dan maksimum 75 hari. $^{5}$

Dari hasil penelitian, dasar teori dan penelitian sebelumnya maka dapat diasumsikan bahwa dengan adanya perawatan metode kanguru terbukti mempersingkat lama rawat juga dapat sebagai incubator yang alami, tidak ada resiko adanya listrik maupun infeksi nosokomial. Dengan semakin cepatnya perawatan di rumah sakit (kurang dari 15 hari) maka dapat mengurangi cost rumah sakit.

Dari hasil penelitian, dasar teori dan penelitian sebelumnya dapat diasumsikan bahwa lama hari rawat pada pasien bayi dengan BBLR diakibatkan karena bayi belum stabil tanda-tanda vitalnya, selain itu kesiapan orang tua untuk merawat bayi di rumah juga masih kurang, sehingga masih perlu latihan supaya mampu merawat bayi BBLR secara mandiri di rumah.

\section{Hubungan PMK dengan lama rawat pada BBLR di RSUD Cengkareng Jakarta Januari - Desember 2018}

Hasil penelitian terdapat hubungan yang signifikan antara rutinitas pelaksanaan PMK dengan lama hari rawat responden BBLR di RSUD Cengkareng Jakarta. Dimana bayi BBLR yang dilakukan PMK maka lama rawatnya akan semakin singkat. Didapatkan nilai OR sebesar 8,318 dengan 95\% $\mathrm{CI}=$ 2,426-28,518yang artinya bahwa semakin rutin dilakukan PMK maka hari rawatnya juga akan semakin singkat, dan sebaliknya semakin tidak rutin dilakukan PMK maka hari rawatnya juga semakin lama. Hal ini menunjukkan bahwa dengan rutin dalam menerapkan perawatan metode kanguru maka hari rawat bayi BBLR juga lebih singkat (kurang dari 15 hari). Namun sebaliknya, jika tidak rutin dalam melakukan perawatan metode kanguru maka lama perawatan bayi BBLR juga semakin lama.

Menyatakan bahwa bayi yang lahir dengan BBLR mudah mengalami kehilangan panas tubuh. Proses kehilangan panas pada BBLR dapat terjadi melalui proses seperti evaporasi, radiasi, konduksi dan konveksi. Perawatan Metode Kanguru (PMK) mendatangkan banyak dampak positif seperti meningkatkan hubungan emosi ibu dan bayi, mengurangi stress pada ibu dan bayi, mengurangi lama menangis bayi, mempersingkat masa rawat di rumah sakit. ${ }^{17}$

Menyatakan bahwa Perawatan Metode Kangguru terhadap lama rawat pada Bayi Berat Lahir Rendah di RSUD Sukoharjo tahun 2016. Dimana hasil penelitian ini didapatkan bahwa Perawatan Metode Kanguru mempunyai pengaruh yang bermakna terhadap peningkatan suhu tubuh, frekuensi denyut jantung, dan saturasi oksigen ke arah normal. Sehingga dapat mempercepat lama hari rawat di perinatologi. Hasil analisa didapatkan (Pvalue $<(0,05) 0,000$. Terdapat pengaruh yang signifikan perawatan metode kanguru terhadap lama hari rawat pada bayi berat lahir rendah sebelum dan sesudah dilakukan Perawatan Metode Kanguru di RSUD Sukoharjo. ${ }^{18}$

Dari hasil penelitian, dasar teori dan penelitian sebelumnya dapat diasumsikan bahwa dengan menerapkan perawatan metode kanguru maka selain mendekatkan ikatan batin ibu dan bayi, juga mengurangi lama hari rawat, serta dengan Perawatan Metode Kanguru biayanya murah, aman dan mudah diterapkan, dapat mempertahankan suhu tubuh bayi, sehingga tanda tanda vital pada bayi lebih stabil. Selain itu BBLR juga sangat rentan dengan kondisi lingkungan sekitar. Jika bayi berat badan lahir rendah tidak mampu menyesuaikan diri dengan lingkungan maka dapat terjadi masalah seperti hipotermi. Hipotermi merupakan keadaan dimana seseorang individu gagal mempertahankan suhu tubuh dalam batasan normal $36-37,5^{\circ} \mathrm{C}$ dan dimana seorang individu mengalami 
penurunan suhu tubuhterus-menerus dibawah $35,5^{\circ} \mathrm{C}$ per rektal karena peningkatan kerentanan terhadap faktor- faktor eksternal.

Patofisiologi hipotermia terjadi bilamana suhu normal pada neonatus berkisar antara $36^{\circ} \mathrm{C}-37,5^{\circ} \mathrm{C}$ pada suhuketiak. Gejala awal hipotermia apabila suhu $<36^{\circ} \mathrm{C}$ atau kedua kaki dan tangan teraba dingin. Bila seluruh tubuh bayi teraba dingin, maka bayi sudah mengalami hipotermi sedang (suhu $32^{\circ} \mathrm{C}$ $<36^{\circ} \mathrm{C}$ ). Disebut hipotermi berat bila suhu tubuh $<32^{\circ} \mathrm{C}$. Untuk mengukur suhu tubuh pada hipotermi diperlukan termometer ukuran rendah (Low Reading Termometer) sampai $25^{\circ} \mathrm{C}$.

Disamping suatu gejala, hipotermi dapat merupakan awal penyakit yang berakhir dengan kematian. Yang menjadi prinsip kesulitan sebagai akibat hipotermi adalah meningkatnya konsumsi oksigen (terjadi hipoksia), terjadinya metabolik asidosis sebagai konsekuensi likolisis aneorobik, dan menurunnya simpanan glikogen dengan akibathipoglikemia. Hilangnya kalori tampak dengan turunnya berat badan yang dapat ditanggulangi dengan meningkatkan intakekalori.

\section{Kesimpulan}

Gambaran karakteristik responden BBLR di ruang perinatologi RSUD Cengkareng, dimana sebagian besar memiliki usia gestasi 34 minggu. Jumlah BBLR yang rutin dilakukan PMK diruang perinatologi RSUD Cengkareng, dimana dari 99 responden BBLR yang dilakukan perawatan metode kanguru yang rutin dilakukan PMK. Lama hari rawat bayi BBLR diruang perinatologi RSUD Cengkareng, dimana dari 99 responden BBLR yang dirawat diruang perinatologi. Terdapat hubungan yang signifikan antara perawatan metode kanguru (PMK) terhadap lamarawat bayi BBLR diruang perinatologi RSUD Cengkareng.

\section{Saran}

Secara Aplikatif Hasil Penelitian ini diharapkan mampu memberikan kontribusi positif pada bayi BBLR yang dilakukan tindakan perawatan metode kanguru (PMK) sebagai alternatif tindakan yang aman, efektif, tidak menimbulkan kontra indikasi baik secara fisik maupun psikologis serta yang paling diharapkan mampu mengurangi lama hari rawat di Rumah Sakit. Diharapkan manajemen keperawatan dapat terus memberikan metode PMK sebagai pelayanan diruang perinatologi.

Secara Teoritis Intervensi yang ini dapat langsung digunakan oleh perawat sebagai intervensi keperawatan dalam mengurangi komplikasi yang terjadi pada bayi BBLR. Hasil dari bentuk intervensi ini selain dapat diintegrasikan dalam pemberian asuhan keperawatan juga dapat dijadikan sebagai intervensi rujukan bagi tatalaksana penangangan bayi BBLR setelah dilakukan aplikasi perawatan metode kanguru (PMK). Oleh sebab itu perlunya belajar perawatan metode kanguru supaya dalam bekerja sudah mahir dalam memberikan palayanan.

Manfaat Metodologis Dihasilkannya intervensi yang aman dan efektif dalam mengelola BBLR, sehingga dapat dijadikan standar operasional prosedur di tiap Rumah Sakit. Dihasilkannya intervensi keperawatan mandiri yang dapat meningkatkan derajat kesehatan serta mengurangi resiko komplikasi dan menurunkan lama hari rawat padaBBLR setelahaplikasi perawatan metode kanguru (PMK). Diharapkan perawatan PMK dapat diutamakan khususnya pada bayi BBLR supaya dapat mengurangi cost rumah sakit dan dapat mengurasi resiko terjadinya nosokomial.

\section{Daftar Pustaka}

1. WHO. Prevalensi Bayi Berat Lahir Rendah. Diakses $02 \quad$ Oktober 2018;http://www.who.int/bblr/countryprofiles/idn_en.pdf?ua $=1 ; 2013$.

2. Pantiawati. Bayi dengan Berat Badan Lahir Rendah. Yogyakarta: Nuha Medika; 2010.

3. Depkes RI. Target Tujuan Pembangunan MDGs. Direktorat Jendral Kesehatan Ibu dan Anak. Jakarta: Depkes RI; 2011.

4. Sindu et al. Kangaroo care compared to incubators in maintaining body warmth in preterm infants. Int J Caring Sci.;8(3):140$151 ; 2015$.

5. Hanum et al. Hubungan Asupan Gizi dan Tinggi Badan Ibu dengan Status Gizi Anak Balita. Jurnal Gizi dan Pangan, 9(1). http://journal.ipb.ac.id/index.php/jgizipangan/ article/viewFile/8256/6458. asi Hanum 825623251-1-PB.pdf. (2015.09.15); 2014.

6. Nurlaila et al. Hubungan pelaksanaan perawatan metode kanguru (PMK) dengan kejadian hipotermi pada bayi Berat Lahir Rendah (BBLR). J Husada Mahakam.;III(9):452-522; 2015.

7. Hidayat A. Metode Penelitian dan Teknik Analisis Data. Jakarta: Salemba Medika; 2011. 
8. Sugiyono. Metode Penelitian Pendidikan. Bandung: Alfabeta; 2013.

9. Nursalam. Konsep dan Penerapan Metodologi Penelitian Ilmu Keperawatan Pedoman Skripsi, Tesis, dan Insrumen Penelitian Keperawatan. Jakarta: Salemba Medika; 2008.

10. Suparyati. Konsep Dasar Keperawatan Anak. Jakarta: EGC; 2013.

11. Yusuke. Yusuke Shimazono; http://www.who.int/bulletin/volumes/85/12/06 -039370; 2010.

12. Sudarti. Asuhan Neonatus Risiko Tinggi dan Kegawatan. Jakarta: EGC; 2013.

13. Yuni. Perawatan Ibu Hamil. Yogyakarta: Fitramaya; 2010.

14. Silvia. Pengaruh Perawatan Metode Kangguru Terhadap Perubahan Berat Badan Bayi Berat Lahir Rendah.Jurnal IPTEKTerapan (Diakses pada $09 \quad$ Agustus 2016). Darihttp://ejournal.unp.ac.id; 2014.

15. Nurhayati. Asuhan Kegawatdaruratan dan Penyulit pada Neonatus. Jakarta: Trans Info Media; 2013.

16. Maryunani. Asuhan Kegawat daruratan Maternal dan Neonatal. Jakarta: Trans Info Media; 2013.
17. Mitayani. Mengenal Bayi Baru Lahir dan Penatalaksanaanya. Padang: Baduose Media; 2010.

18. Sulistyowati. Pengaruh Perawatan Metode Kanguru Terhadap StresFisilogis Pada Bayi Berat Lahir Rendah Di RSUD Sukoharjo Tahun 2016. (Diaskes pada10 April 2017). Darihttp://www.stikeskusumahusada.ac.id/; 2016. 